ISAHP 2001, Berne, Switzerland, August 2-4, 2001

\title{
COMBINE GAME THEORY AND AHP TO CHOOSE STRATEGIC ORIENTATION IN TECHNOLOGY DEVELOPMENT - INDONESIAN CASE -
}

\author{
Ilham Said ${ }^{1}$ \\ Institut Pendidikan dan Pembinaan Manajemen - Jakarta \\ University of the Philippines - College of Business Administration
}

Keywords: game theory, AHP, interactive, collaboration

Summary: The objective of this paper is to give direction to the three main economic players (industry, government and academician) in determining their strategic orientation in technology development. The model will be built in interactive framework where in making decision each player considers other possible strategic choices. A three-dimension game theory combined with an interactive decision structural model of AHP will be used to find the solution. The results reveal that collaboration strategy give the highest outcome for the three players. It recommends industry and academician to make collaboration in undertaking innovation while the government should let an independent organization to manage technology development.

\section{Introduction}

Technology has been pointed out as the key success factor to win competition. Competitive success increasingly goes to enterprises that can absorb, apply and coordinate new technological development quickly. Then, intense global industrial competition has generated volatile dynamics of global technological changes. Those changes make competitive patterns become more complicated. As the result, firms could not compete merely as single firm anymore, they must be backed up with policies and efforts from the whole industry, government and other institutions.

Pacific Rim, where Indonesia located, according to Simon [1995], has several unique characteristics. Those unique conditions of Pacific Rim bring both opportunities and threats for Indonesia. For taking advantages furthermore, Simon points out that technology development is the key. One crucial problem in Indonesia is disintegrated effort in technology development. Government has emerged as the initiator, but 'conflict of interests' among government officials make industrial priorities overlooked. That is why, according to Luluhima [1996] demanding for reorganizing of technology development in Indonesia in systematic way and integrated bases is felt very urgent.

The paper will focus on what strategic orientation should be taken by the economic players (government, industry, and academicians) to organize technology development. Analysis will be done based on an interactive framework. A previous survey is conducted to know what those each players' decisions when they are facing other players' decisions (what-if questions).

\section{Research Design}

As mentioned by Betz, [1994] there are three dominant players of technology management who determine success of technology development in a particular country, namely: government, industry and academician. Interactions among them are very crucial and might be unique for each country. Those three players are called by Minden and Poh-Kam [1996] as a tripartite responsibility and by Luluhima [1996] as innovation

\footnotetext{
${ }^{1}$ Undersupervised by Dr. Elvira A. Zamora, the dean of the College of Business Administration, University of the Philippines.
} 
triangle. Finding the best interactions of those three players are consistently supported by some researchers. For instance: Davis and Smith from Canada [1996], Chen from Hongkong [1995], Chiang from Taiwan [1995], Kim [1995] from Korea, Sripaipan [1995] from Thailand, Said [1995] from Malaysia [1995], Luhulima from Indonesia [1996], Yikang et.al. [1995] from China and Minden and Poh-Kam [1996] from Singapore. The other players that might be involved are international agencies, as suggested by and PohKam [1996], or research centers, like in Canada where research centers dominates efforts in technology development [Davis et al. 1996], or non government organizations whose main concern is environmental issues, as suggested by Madu [1996]. However, in Indonesia, the roles of those three institutions in technology development are very small.

\subsection{Methodology}

In this study game theory will be used combined with Analytical Hierarchy Process (AHP). Game theory has been accepted widely as the best tool for interactive decision making, while AHP [Saathy, 1982] on the other hand has been accepted also as the best tool in interpreting qualitative decisions into quantitative scores, which is the basic requirement for game theory. Game theory is used to simulate interactively each possible combination of alternative decisions selected by the three players. Analytical Hierarchy Process (AHP) is used to determine pay-off of each combination.

AHP is designed to solve complex and multiple-criteria problems. The process requires decision-maker to give judgment about the relative importance of each criterion and then specify a preference on each criterion for each decision alternative. The output of AHP is a prioritized ranking indicating the overall preference for each of the decision alternatives. In this paper, that prioritized ranking is considered as the pay-off of the game theory which can be translated as "how much (level of preference) of the decision maker (player) will get when he or she choose that particular strategy considering other player's decision".

Each player in this study has three options of strategies. Each strategy is mutually exclusive, meaning only one of them can be chosen. Therefore there will be 27 possibilities of interaction $(3 * 3 * 3)$. These interactions will be arranged in three dimension box [figure 1]. Each unique interaction is placed in one box where each box consists of three number reflect outcome (or usually called pay-off) of each player when choosing any strategy. For instance, box I-I-I contains three outcomes where each represents an outcome when player choose strategy I. Hence, there will be twenty seven pay-offs. Each of them contains three score represent to score of each player.

Figure 1: Three dimensions Game-Theory structure

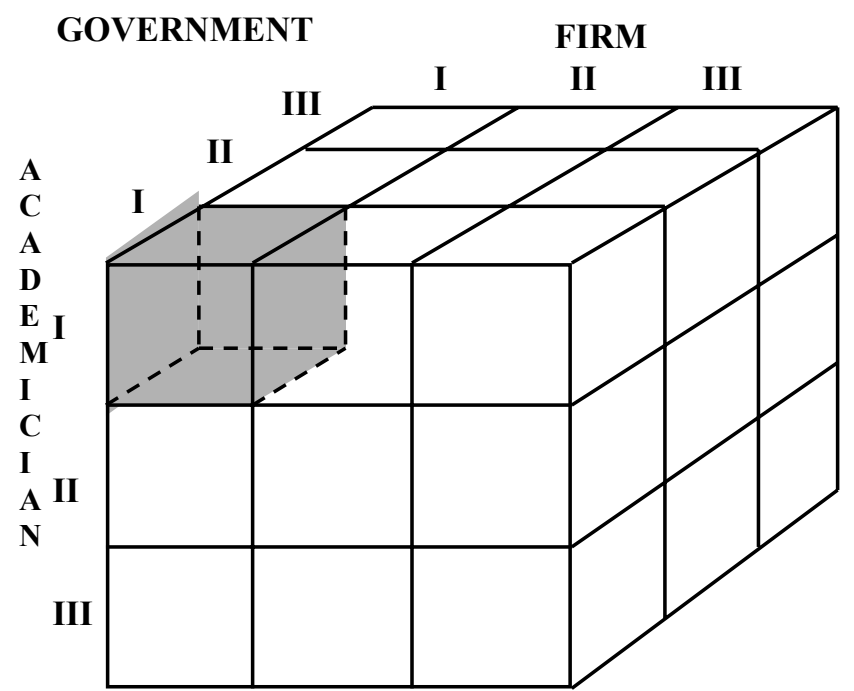

Adapted from Enos, John L. [1985].

Proceedings $-6^{\text {th }}$ ISAHP 2001 Berne, Switzerland 
Due to difficulties in interpreting three dimension games, the study will simplify them into two dimension diagram wherein only two players face to face each other (one as the first mover while the other as the follower) while the third player move is given. Figure 2 illustrates a game where academician is appointed as the first mover, firm as the follower, and government is assumed to have moved with the first choice.

\section{Figure 2: Two-dimension game theory}

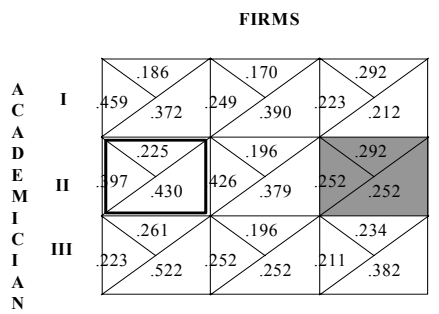

GIVEN: GOVERNMENTI

The study observes two possible results: 'ideal choice,' (sometimes called 'reasonable outcome') obtained from non-cooperative game and 'stylised outcome,' the highest total outcome for all participants as a group obtained from a cooperative game. Non-cooperative game apply minmax criterion method which means the first mover will minimize his maximum losses whenever the resulting choice of strategy can not be exploited by the other participant to then improve his position. Cooperative game that may bring higher pay-off to all players is observed as well, reminding that players may do that, particularly when one of them has ability or interest to initiate it. For instance, figure 2 shows that strategy II for academician, I for firm, and I for government is the stylised outcome, while strategy II for academician, III for firm, and I for government is the ideal choice.

Figure 3: Research Stages

\begin{tabular}{|c|c|}
\hline \multirow[t]{4}{*}{$\begin{array}{l}\text { SECONDARY } \\
\text { DATA }\end{array}$} & \begin{tabular}{|l}
\multicolumn{1}{|c}{ PREPARATION } \\
Research Design \\
Decision Structural Model \\
Strategic Options \\
Determinant Factors (Criteria) \\
Questionnaire
\end{tabular} \\
\hline & $\begin{array}{l}\text { DATA GATHERING } \\
\text { Compare criteria and rate alternatives based on intensity scale }\end{array}$ \\
\hline & $\begin{array}{l}\text { AHP PROCESSING } \\
\text { Pair Comparison of Criteria } \longrightarrow \text { Weighted Scores } \\
\text { Rating Process } \longrightarrow \text { Alternative's Scores }\end{array}$ \\
\hline & $\begin{array}{l}\text { INTERACTIVE FRAMEWORK ANALYSIS } \\
\text { Develop three-dimension matrix of the game theory } \\
\text { Enter alternative's scores as the pay-off } \\
\text { Make "what-if" interpretations }\end{array}$ \\
\hline
\end{tabular}

Proceedings $-6^{\text {th }}$ ISAHP 2001 Berne, Switzerland 


\subsection{Research stages}

The research's stages are illustrated in figure 3. Respondents filled a questionnaire to express their opinions and preferences. Three kinds of question has guided them in comparing criteria used to select strategy of technology development, and in rating the strategic alternatives against an intensity scale.

\subsection{Decision Structural Model}

\subsubsection{Strategic Options}

In order to avoid being trapped to a high-complicated model, strategic options are limited to three. Consequently, they should cover the extreme choices. Those three choices are derived based on estimations toward the most interesting issue for each player toward technology development.

\subsubsection{Government}

For government the issue is "what level of control toward technology development." It corresponds to the government's responsibility to the society [Starling,1998]. The extreme choice of that issue should be:

I. Fully control it

II. Let an independent organization do it,

III. No control at all.

The first and the third choice are extreme choices of the level of control. Another extreme that laying between those two points is to let independent organization manage technology development. As mentioned by Gregory Tassey [1996], when the market failure and thus underinvestment is particularly severe, as presently happen in Indonesia during economic crisis, public participation in cooperative research is required.

It is assumed that government has abilities to implement any of those three choices. Although it should be realized that in some cases it might not be implemented completely. For instance, the constitution has stated that government must fully control all researches that may hurt public interest, or may cause big disasters. That is why, only government can do nuclear research, and weapon manufacturing.

\subsubsection{Companies}

The most concern of companies in technology development, according to Betz [1994], is "how to develop a new technology in term of making new product design." Thus the question should be how they do that. Thus in this study the companies will be given choices to:

I. Undertake independent innovation,

II. Collaborate with other institutions, or

III. Borrow technology

Stuart's [1995] founded that there was a strong correlation between R\&D investment and sales growth across all industry group. Also, companies that invest a greater portion of their sales in R\&D experienced the fastest growth rates. Little evidence was found of the reverse relationship.

Idea of collaboration actually emerges from attempting to reduce the cost of $R \& D$ by sharing the burden (and risks) with other firms or with the public sectors. Rebecca Morales [1994] founded that collaboration can generate innovation.

In general, it is assumed that companies can afford the three choices. Although it might not occur in some industries, like in the high sophisticated industry, companies might not have resources to undertake innovation independently. Likewise, transfer of technology may be prohibited in some industries since the 
government wants to protect domestic industry. For instance, cigarette and textile are discouraged to implement technology that will mechanize production processing and then replace human involvement.

\subsubsection{Academicians}

For academician, the main issue is "who should initiate the research of technology development." Thus the study provide choices for academicians as following:

I. Initiate to do research,

II. Collaborate with other institution (joint research), or

III. Do research for an outside company or institution with the initiative coming from the company/institution.

There is arguing toward the first and the third choices. Some academicians according to Roberts and Malone [1996] perceive a threat to intellectual freedom and worry that value systems may change through increased exposure to commercial practices. Collaboration research is another option where the results are expected to give benefits toward academician and customer. Thus, the research goal and methodology can be determined together in such a way that the two parties' objectives can be fulfilled proportionally. The willingness of academician to do collaboration in technological research according to Oakey and Pearson [1995] has strengthened relationship among university, industry, and government in improving technology.

\subsubsection{Determinant Factors}

Before selecting any alternatives normally the decision-maker weights first the impact. The impact influences what criteria will be applied in making decision, indeed in some cases, that impact is used directly as a criterion.

\subsubsection{Government}

In choosing alternative to organize technology development, government most likely considers three potential impacts, they are: cost, political image, and technology performance. Cost is considered since government planning is limited by budget. All government expenditure must be transparent and accountable, so spending that budget must be careful so that each activity include technology development must be considered accurately. It is supposed to become more crucial in this current economic crisis that has forced government to slash many projects.

Political image will be set as factor that will be watched by government to ensure their sustainable power, which is examined periodically five year. As mentioned by Starling [1998] government can not ignore the political environment of any decisions. So, all policies, include technology development, should satisfy people's interest as much as possible. For instance, when choosing which industrial sector that must be developed and be subsided, government should choose industry that has great economical impact to the low class society, to the small business companies, and to the greater labor-force companies. However, government's interest in political image, underscored by Justman and Teubal [1996] should not be overemphasized but should be searched its balance with other objectives.

Government should prioritize technology performance to boost indigenous technology that will reduce the reliance on the high cost imported technology. However, government usually underestimates the importance of supporting technology performance especially in building technological infrastructures. [Gregory Tassey, 1996]. As the typical product life cycle shortens and as demands for product flexibility and greater productivity and quality increase, government will be forced to supply more of that technologybased infrastructure. 


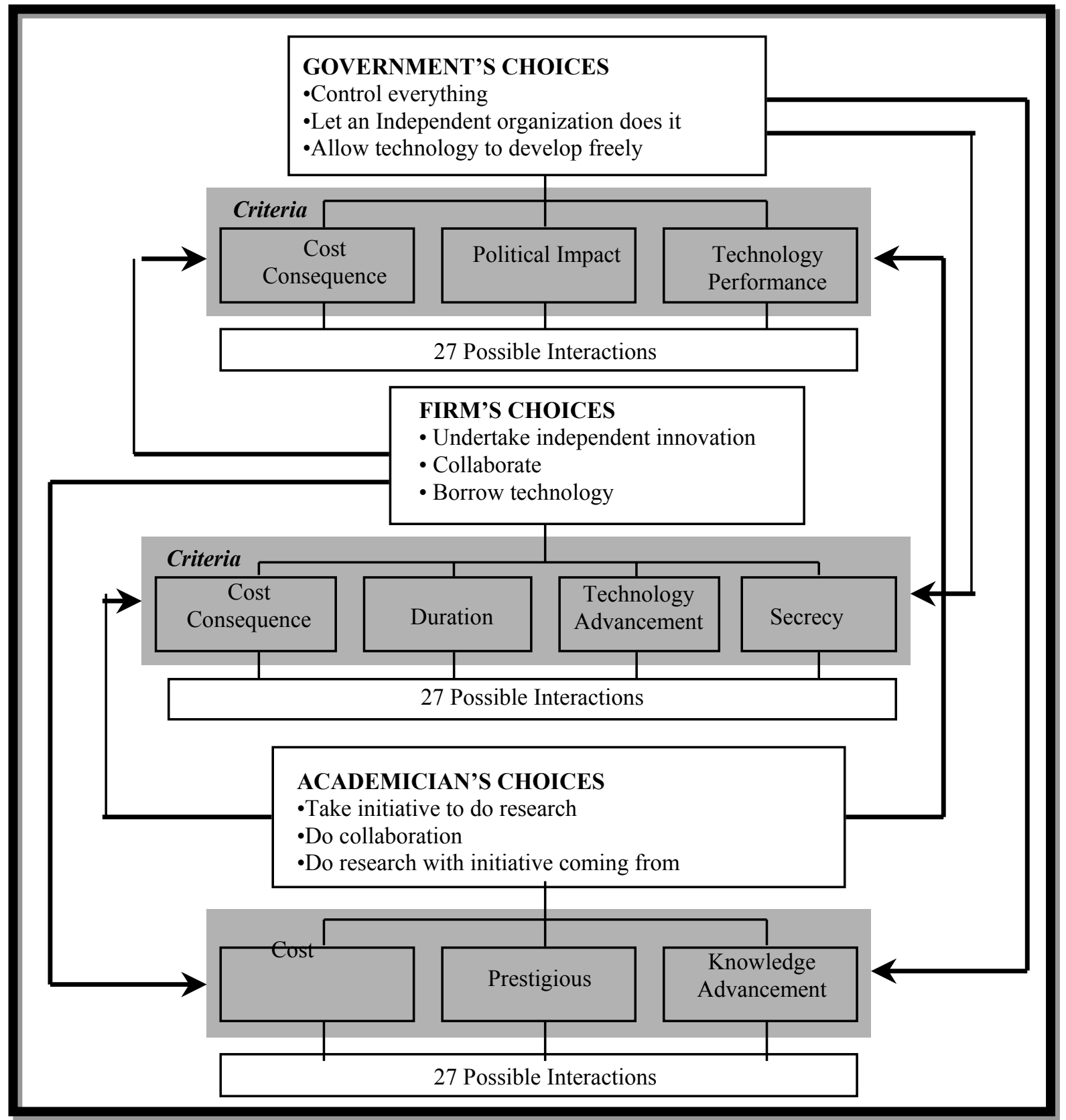

Figure 3: Decision Structural Model

\subsubsection{Firms}

Considering that most firms focus their objectives on profitability and competitiveness, the study will observe four determinant factors: cost, duration, technology advancement, and secrecy. Reducing cost is substantial factor to push marketable price, where the lower marketable price the higher competitive advantages. Since technology development expenditure is usually charged as a fixed cost, so the higher its cost the larger volume-of-sale needed to cover it and the longer time to achieve break-even-point (BEP). To lower BEP, price must be increased but the product's competitiveness will suffer. If duration of undertaking innovation can be cut, more chances to get bigger profit since as the first mover the company 
can enjoy a "temporary monopolist" before the follower enters [Maidique et al. 1978]. Betz [1994] supports that idea and underlines that technological innovation creates competitiveness only when used in a timely fashion.

Technology advancement, particularly in the matter of the quality, is important to be considered by the companies, since the more advance the companies in a particular technology, the more competitive them and the harder to be imitated. Lowel Steele [1988] as cited by Betz [1994], emphasized that new technology without significantly superior performance will never succeed as an innovation. However, Betz reminds that that superior performance should be in the proper ratio to cost. Secrecy is considered because of its importance to extend the profitable "temporary monopolist".

\subsubsection{Academicians}

There are three criteria will be applied for academician. They are knowledge advancement, cost, and prestige. Unlike firms, the academician's focus on technology development is usually non profit and tend to be an ideal objective. For instance one of academician focus is to advance the realm of knowledge [David and Foray 1996]. That is why the factor of knowledge advancement is included as a criterion.

The factor of cost is included with the reason that, in many cases academicians are so reliant on subsidy coming from government or foundations, so to attract the sponsor, cost must be pressed as lower as possible [Gibson, 1994 and Lee, 1996].

The last factor is prestige. After doing a successful research, institution might get higher level of reputation. Many institutions are accredited in the higher ranking due to their abilities to do intensive researches that give big impacts toward knowledge advancement or toward the people's welfare. Complete decision structural model is provided in Figure 3.

\section{Respondents}

Population to be studied is composed of three group of respondent: government officers, academicians, and business practitioners. A total of 300 questionnaire (100 for each group) have been distributed, but only 70 $(30 \%)$ of them are returned with 69 can be processed. There are 21 academicians, 25 government officers and 23 of business practitioners. In collecting data, some difficulties were faced related to unstable political situation and economic crisis engulfing Indonesia. Amid high tension of people power where demonstrations were done everyday, campuses were closed for public, most of main road was blocked, and many companies were doing lay-off, it was very risky to move from one place to other places. Therefore, the questionnaires were not distributed randomly to many places but focusing on a few selected institutions. For government group, three government institutions has been chosen, two government agencies: BPPT (Agency for the Assessment and Application of Technology), and BATAN (National Atomic Energy Agency), and one organic department (Department of Transportation). BPPT is selected for the reason that BPPT is the government agency that is formally given authority to do national scale researches on technology application. Before Habibie appointed as the president, he has founded and led BPPT for more than 20 years. BATAN is in the same mission with BPPT, but focus on atomic application. Opinions from BPPT and BATAN are assumed to represent government's opinion from the researcher point of view. Respondents from Department of Transportation are expected to represent opinion from bureaucracy.

Opinions from academicians are picked from IPPM (Institute for Management Education and Development) and STM-PPM (PPM School of Business), besides considering accessibility, most of PPM's professional staffs have various knowledge disciplines, not mere from economic or business management. Thus it is assumed that their opinions can represent academicians. Meanwhile, business practitioners are represented by Gaya Motor and United Tractor, those companies are member of Astra Group. Astra Group is considered as the leading company in practicing modern management in Indonesia.

Proceedings $-6^{\text {th }}$ ISAHP 2001 Berne, Switzerland 


\section{Results}

This research reveals that alternative II-II-II dominates the game, in fact, all of the six possibilities end with strategy II-II-II and interestingly, they coincide the ideal and stylist outcome. It implies that when given player assumed choose strategy II, then the best choice for other players must be strategy II as well. For instance, when government choose strategy II of let independent organization control technology development, then the best choice for firms is strategy II of doing collaboration, and also for the academician is strategy II of doing research collaboration.

Coinciding of the ideal and the stylist outcome means that higher result can be achieved automatically, so it is unnecessary to force cooperative game, remind that cooperative game requires additional cost for negotiation. That tendency of choosing alternative II-II-II reflects the current situation in Indonesia, where in one side, government has been failed because of its over-control toward technology development while on the other side, non-government organizations are not ready to take it over yet. Therefore transition step like alternative II-II-II is preferred.

In general, the research results hint the dominance of strategy II of collaboration. The result of strategy II is suggested in 13 of 18 possibilities. It shows that although each player each has own unique missions, they are strongly suggested to make collaboration with other institution, which of course, might affect their mission achievement.

For the government, the result shows that strategy II is chosen five times, strategy I is once, while strategy III is not suggested. This result apparently refers to the failure of the past strategy that tends to be in strategy I of control everything. The strategy III of let technology develop freely is not much suggested since infrastructure and private sector's capabilities have not ready to support it. Thus, strategy II of let independent organizations to manage technology development, is seen as a transition stage, before done it totally by private sectors and let market mechanism control it automatically.

The results suggest firm to implement strategy II and III, while strategy I is not recommended at all. It is interesting that apparently firms willing to do collaboration only if other players send signals of willingness to do collaboration as well. It shows us how firms doubt toward collaboration when they think that other players are not ready to do that. It can be accepted logically when knowing firm's position as the front liner of the new technology application, meaning whenever they fail in a new technology application, they will take the most considerable responsibilities with possible extensive impacts toward profitability, image, or even its existence.

The same reason apparently behind the firm's rejection to undertake innovation internally and independently, aside from the fact that domestic infrastructures both physical and brain (human resources) are not ready to support it. This situation support the Luluhima [1996] suspicious that none of the companies in Indonesia had developed an indigenous R\&D facility to conduct basic and applied research. For the long-term, actually that strategy may cause much disadvantageous than benefits. As Anuwar Ali, [1995] observation to NIE's countries, he highlighted the fact that indigenous technological advance was the only way to stay alive in the game of global competition. To push indigenous technology development, private sectors are expected to take initiation fueled with significant support from all other economic players include government and academicians.

This survey results suggest academician to do strategy II of make collaboration regardless other player's strategy. This is an interesting result that might be prompted by the current turmoil economic problems. Academician perceives that only integrated and simultaneous efforts which can address Indonesian's current problems in improving technological strengthening. They might be still in the crossroads whether to put their intellectual freedom of doing their own research ahead or the applicability of the research results. That is why, the tendency of doing collaboration dominates the result is reasonable since it can 
accommodate those two contradictory principles. Doing collaboration, academician somehow still could impress his own academic interest without disregarding the practical purposes that needed by industries.

\section{Conclusion}

Game theory, in the last decades has emerged as a powerful method to describe and to give wayouts when facing interactive problems solving. However, one big constraint to make it more applicable seemingly is in determining alternative pay-offs . As mentioned by John L. Enos (6) that "to anyone who believes that game-theory offers useful approach to the choice of technology (one kind of crucial strategic choice) priority in research should be given to the estimation of pay-offs". Especially when the problems are dominated by qualitative considerations like what is usually happen in strategic problems. Qualitative inputs can not be processed directly by game theory. They should be translated first into quantitative inputs (pay-offs). This paper shows how AHP can be used to solve this problem. One of the advantages of AHP is its ability to translate qualitative considerations into quantitative results. However, use AHP solely will face difficulties to solve interactive problems. Thus combine those two powerful concepts will give better way-outs in solving interactive problems.

Collaboration strategies dominate the highest outcomes. The research founds that the best strategies for the three economic players in managing technology development are for the government is let and support independent organization to do it, for the company and academician are to engage in research collaboration. This result shows that the three players realize that technology development is a big issue. To deal with that, they need to unite their efforts and to support each others.

\section{References}

1. Alam, Dipo. 1995. Building a Strong S\&T in Indonesia: Policies in a Transitional Economy. Technological Trajectory of the Pacific Rim. Simon, Denis Fred (editor). New York. M.E. Sharpo, Inc., 186-209

2. Ali, Anuwar. 1995. Science and Technology Collaboration at the Regional Level: Lessons from ASEAN. Technological Trajectory of the Pacific Rim. Simon, Denis Fred (editor). New York. M.E. Sharpo, Inc., 135-146

3. Betz, F. 1994. Strategic Technology Management. New York: McGraw-Hill, Inc.

4. Cheng, E. Yegin. 1995. Technology Management in Hong Kong, Too Late? Developing Technology Managers in the Pacific Rim. Minden, K. and Poh-Kam, W. (editors). New York: M.E. Sharpe,

5. Chiang, Jong-Tsong. 1995. Development of Technology Management in Taiwan. Developing Technology Managers in the Pacific Rim. Minden, K. and Poh-Kam, W. (editors). New York: M.E. Sharpe,

6. David, Paul A. and Foray, D. 1996. Information distribution and the growth of economically valuable knowledge: a rationale for technological infrastructure policies. Technological Infrastructure Policy: An International Perspective. Teubal, et al (editors). Dordrecht: Kluwer Academic Publishers, 87-116

7. Davis, Charles H, and Smith, Richard. 1996. Management of Technology and Technological Change in Canada: Learning and Teaching Innovation and Competitiveness. Developing Technology Managers in the Pacific Rim. Minden, K. and Poh-Kam, W. (editors). New York: M.E. Sharpe,

8. Enos, John L. 1985. A Game-Theoritic Approach to Choice of Technology in Developing Countries. Technology, Institutions, and Government Policies. James, Jeffrey and Watanabe, Susumu (editor). The Mac-Milan Series of ILO studies. 47-79.

9. Gibson, David V., Rogers, Everett M. 1994. R\&D Collaboration on Trial. Harvard Business School Press.

10. Justman, M. and Teubal, M. 1996. Technological infrastructure policy (TIP): creating capabilities and building markets. Technological Infrastructure Policy: An International Perspective. Teubal, et al (editors). Dordrecht: Kluwer Academic Publishers, 21-58

11. Kim, Hi-Soo. 1995. Management of Technology in Korea. Developing Technology Managers in the Pacific Rim. Minden, K. and Poh-Kam, W. (editors). New York: M.E. Sharpe,

12. Lee, Yong S. 1996. Technology Transfer and the Research University: A search or the boundaries of university-industry collaboration. Research Policy Journal Vol: 25. 
13. Luluhima, C.P.F. 1996. Management of Technology: the Indonesian case. Developing Technology Managers in the Pacific Rim. Minden, K. and Poh-Kam, W. (editors). New York: M.E. Sharpe, 194212.

14. Madu, Christian Ndubisi. 1996. Managing Green Technologies for Global Competitiveness. Quorum Books. London.

15. Morales, Rebecca. 1994. Flexible Production Development and Public Policy. Management of Technology and Regional Development in a Global Environment. Lefebvre, Louis A. and Lefebvre, Elisabeth.(editors). London: Paul Chapman Publishing.

16. Maidique, Modesto A. and Patch, Peter. 1978. Corporate Strategy and Technological Policy. Readings in the Management of Innovation. Tusman, Michael L and Moore, William L (editors). London: Pitman Books Limited, 273-285.

17. Minden, Karen and Poh-Kam, Wong. 1996. Introduction: The Technology Management Challenge. Developing Technology Managers in the Pacific Rim. Minden, K. and Poh-Kam, W. (editors). New York: M.E. Sharpe,

18. Oakey, Ray P. and Pearson, Alan W. 1995. Innovation, Technology and Regional Development. Management of Technology and Regional Development in a Global Environment. Lefebvre, Louis A. and Lefebvre, Elisabeth.(editors). London: Paul Chapman Publishing.

19. Poh-Kam, Wong and Minden, Karen. A Comparative Viem of Pacific Rim MOT Approaches: Implications for Policy. Developing Technology Managers in the Pacific Rim. Minden, K. and PohKam, W. (editors). New York: M.E. Sharpe,

20. Poh-Kam, Wong. 1996. Developing Technology Managers in Singapore: Issues and Challenges. Developing Technology Managers in the Pacific Rim. Minden, K. and Poh-Kam, W. (editors). New York: M.E. Sharpe,

21. Roberts, Edward B. and Malone, Denis E. 1996. Policies and Structures for Spinning off New Companies from Research and Development Organizations. R\&D Management 26, 1, 1996: 17-48. Blackwell Publishers Ltd.

22. Saathy, Thomas L. 1982. Decision Making for Leaders: The Analytical Hierarchy Process for Decision in a Complex World. California: Lifetime Learning Publications.

23. Said, M. Rahimah. 1995. Developing Technology Managers: The Malaysian Experience. Developing Technology Managers in the Pacific Rim. Minden, K. and Poh-Kam, W. (editors). New York: M.E. Sharpe,

24. Simon, Denis Fred. 1995. Globalization, Regionalization, and the Pacific Rim. Technological Trajectory of the Pacific Rim. Simon, Denis Fred (editor). New York. M.E. Sharpo, Inc.,

25. Sripaipan, Chatri. 1995. Management of Technology in Thailand. Developing Technology Managers in the Pacific Rim. Minden, K. and Poh-Kam, W. (editors). New York: M.E. Sharpe,

26. Starling, Grover. 1998. Managing the Public Sector. Fifth Edition. Harcourt Brace College Publishers. Orlando, Florida

27. Stuart, George F. and Frater, Paul R. and Roses, Dennis.1995. The Development of Science and Technology Policy in a Small and Open Economy: The New Zealand Experience. Management of Technology and Regional Development in a Global Environment. Lefebvre, Louis A. and Lefebvre, Elisabeth.(editors). London: Paul Chapman Publishing.

28. Tassey, Gregory. 1996. Infratechnologies and economic growth. Technological Infrastructure Policy: An International Perspective. Teubal, et al (editors). Dordrecht: Kluwer Academic Publishers, 59-86

29. Yikang, Wu. and Guilan, Dong. and Mengxin, Sun. 1995. Management of Technology in China. Developing Technology Managers in the Pacific Rim. Minden, K. and Poh-Kam, W. (editors). New York: M.E. Sharpe, 